\title{
Paduan Zona Agro Edu Tourism (AET) dan Plant Factory with Artificial Lighting (PFAL) pada Vertical Urban Farming
}

\author{
Alifaldo Arnello dan Bambang Soemardiono \\ Departemen Arsitektur, Fakultas Arsitektur Desain dan Perencanaan, Institut Teknologi Sepuluh \\ Nopember (ITS) \\ e-mail: bbsoem@arch.its.ac.id
}

\begin{abstract}
Abstrak-Teknologi pertanian selalu mengalami perkembangan. Salah satu wujud perkembangan terbaru teknologi yang digunakan dalam pertanian adalah vertical farming. Vertical farming telah dilakukan di negara-negara maju seperti Amerika Serikat, Kanada, Jepang, Korea dan China. Agar masyarakat Indonesia sadar, tahu dan mengerti akan perkembangan teknologi pertanian tersebut maka diperlukan adanya objek arsitektur yang menyediakan dan mendidik masyarakat mengenai perkembangan teknologi pertanian, dalam hal ini berupa vertical farming. Metode desain yang digunakan dalam merancang vertical farming adalah metode tipologi, yaitu metode penyusunan elemen-elemen yang telah ditentukan. Dalam desain ini elemen-elemen yang telah ditentukan adalah kebutuhan sistem dan ruang untuk vertical farming. Kebutuhan sistem dan ruang ditentukan dari tipologi vertical farming dan preseden vertical farming yang telah dibangun. Penyusunan mengacu kepada tujuan fasilitas sebagai edukasi, tourism dan produksi pangan menggunakan teknologi vertical farming. S ehingga dihasilkan dua zona, yaitu zona agroedu-tourism (AET) dan zona plant factory with artificial lighting (PFAL) yang efisien dalam penggunaan lahan.
\end{abstract}

Kata Kunci-AET, Efisiensi, PFAL, Tipologi, Vertical Farming.

\section{PENDAHULUAN}

$\mathrm{T}$ EKNOLOGI pertanian selalu mengalami perkembangan. Terasering, roof garden, vertical garden, greenhouse dan lain-lain merupakan wujud dari perkembangan pertanian tersebut pada masanya. Salah satu wujud perkembangan terbaru teknologi dalam pertanian adalah vertical farming.

Vertical farming adalah praktek menghasilkan makanan dan obat-obatan di lapisan vertikal yang ditumpuk, permukaan miring vertikal dan/atau terintegrasi dalam struktur lain (seperti di gedung pencakar langit, gudang bekas atau kontainer pengiriman) (Gambar 1). Perkembangan teknologi ini perlu untuk diketahui dan dipelajari oleh masyarakat karena metode bertanam vertical farming ini dapat mempermudah dan meningkatkan efektifitas dalam pertanian.

Vertical farming telah dilakukan di negara-negara maju seperti Amerika Serikat, Kanada, Jepang, Korea dan China dengan sebutan Plant Factory with Artificial Lighting (PFAL) atau Indoor Vertical Farms (Gambar 2) [1].

Agar masyarakat Indonesia sadar, tahu dan mengerti akan perkembangan teknologi pertanian ini maka diperlukan adanya fasilitas yang menyediakan dan mengedukasi perkembangan teknologi pertanian, dalam hal ini berupa vertical farming.

Rancangan Verticalfarming akan dibagi menjadi dua tipe, yaitu tipe PFAL yang berfokus pada operasional fasilitas dan
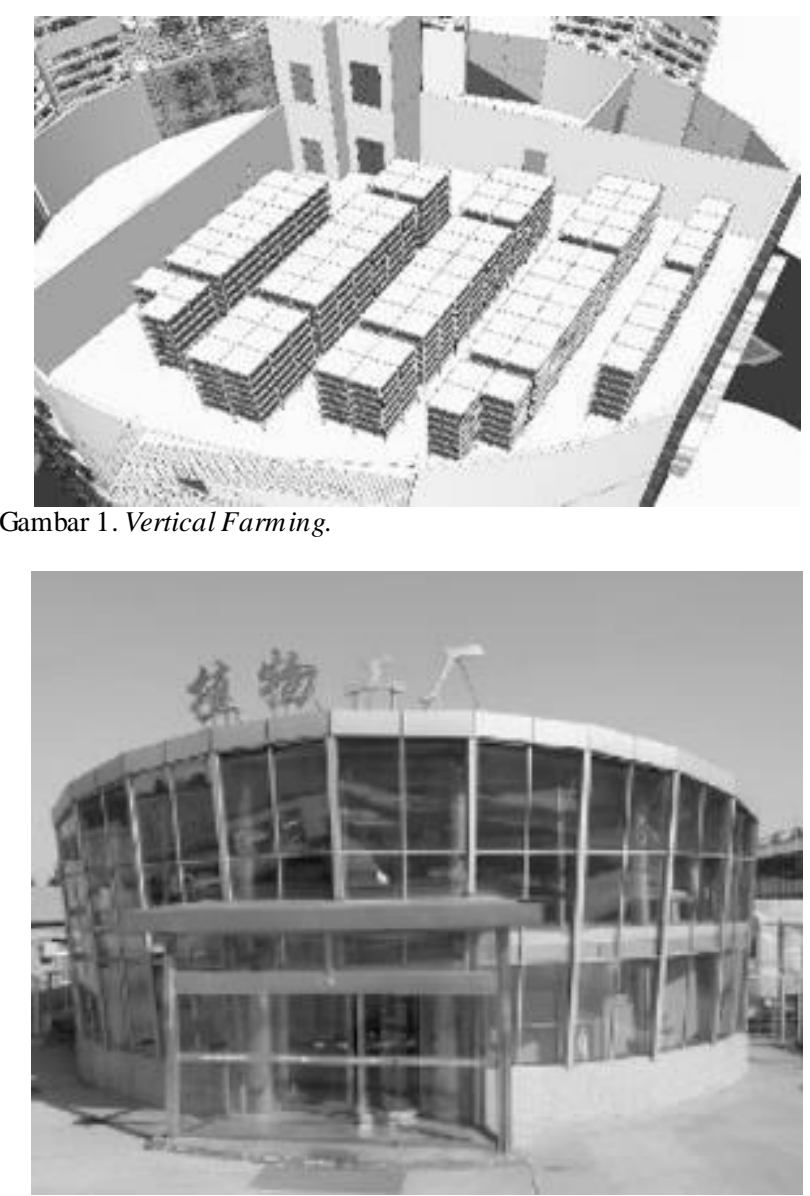

Gambar 2. Vertical Farming yang telah dibangun di China.

produksi pangan dan tipe Agro-Edu-Tourism (AET) yang berfokus pada edukasi dan wisata agriculture (Gambar 3).

Jalan Kayoon dipilih sebagai lahan untuk fasilitas ini karena jalan ini berpotensi sebagai kawasan agrowisata dan ditambah berdasarkan Perda Kota Surabaya tentang Rencana Tata Ruang Wilayah (RTRW) Kota Surabaya Tahun 20102030 kawasan ini akan dijadikan sebagai kawasan agrowisata [2]. Jenis tanah aluvial pada Jalan Kayoon juga cocok untuk melakukan pertanian [3].

Permasalahan desain yang diangkat adalah bagaimana secara arsitektural mengharmonisasi antara fasilitas PFAL dengan Agro-Edu-Tourism, bangunan tinggi dengan lanskap, vertical farming dengan eksisting pas ar bunga, dengan tetap memperhatikan efisiensi penggunaan lahan. Sehingga dari permasalahan di atas dihasilkan lima kriteria sebagaiberikut:

1. Mampu menyediakan ruang yang dapat menyediakan fasilitas PFAL dan Agro-Edu-Tourism yang harmonis. 


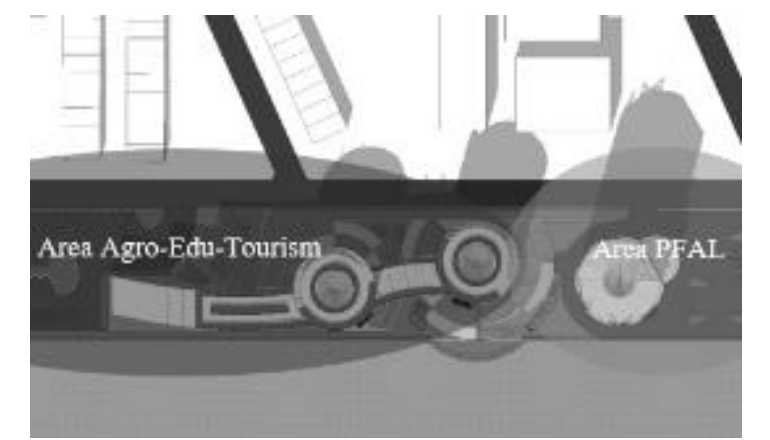

Gambar 3. Area Agro-Edu-Tourism dan Plant Factory with Artificial Lighting.

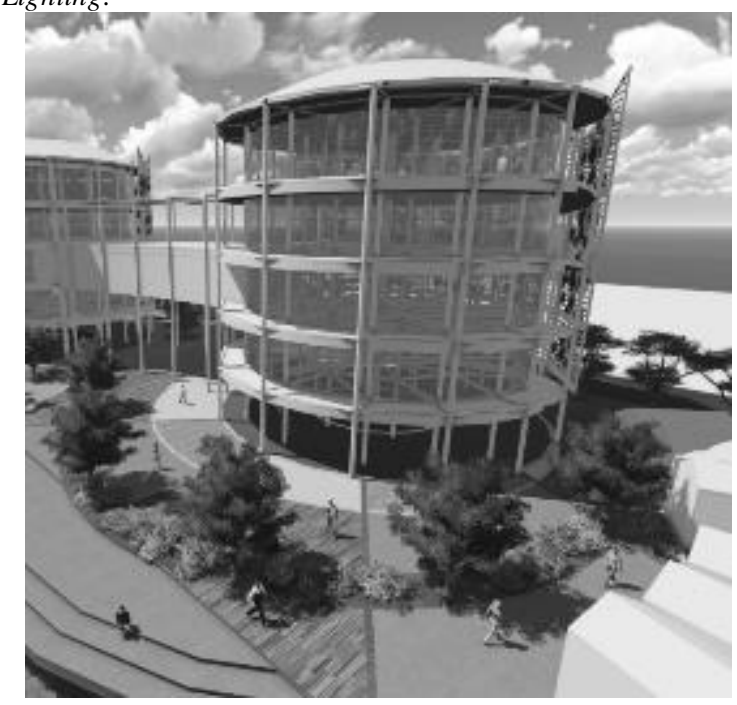

Gambar 4. Vertical Farming dan Taman.

2. Mampu menyediakan culture room yang steril pada fasilitas PFAL.

3. Mampu menyediakan sirkulasi dan jarak pandang yang baik pada fasilitas Agro-Edu-Tourism.

4. Mampu menyediakan fasilitas Vertical Farming yang harmonis dengan eksisting pasarbunga.

5. Efisien dalam penggunaan lahan.

\section{EKSPLORASI DAN PROSES RANCANG}

Vertical Urban Farming yang akan dirancang adalah objek arsitektural yang memfasilitasi produksi, pemasaran dan wisata agrikultur. Produksi agrikultur akan dilakukan melalui vertical farming (bahan pangan) dan taman di lansekap (bunga) (Gambar 4). Pemasaran agrikultur akan dilakukan melalui supermarket dan toko bunga (Gambar 5). Daya tarik utama untuk wisata adalah vertical urban farming dan pasar bunga.

Fasilitas tidak hanya berfungsi memproduksi agrikultur tetapi juga memasarkan dan menjadi objek agriwisata. Oleh karena itu pengguna dari objek arsitektural ini tidak hanya karyawan dan petani, tetapi juga pedagang / penjual, pengunjung, wisatawan mancanegara dan wisatawan dalam negeri.

Berdasarkan kajian is u dan tujuan perancangan, didapatkan beberapa kriteria desain yang dapat digunakan sebagai batas an dalampencarian lahan untuk objek arsitektur. Kriteria lahan yang dapat diterapkan antara lain adalah:

1. Lahan memiliki potensi atau berada di kawasan yang memiliki peruntukan lahan untuk agrowisata.

2. Lahan berada di kawasan yang memiliki kepadatan penduduk yang tinggi.

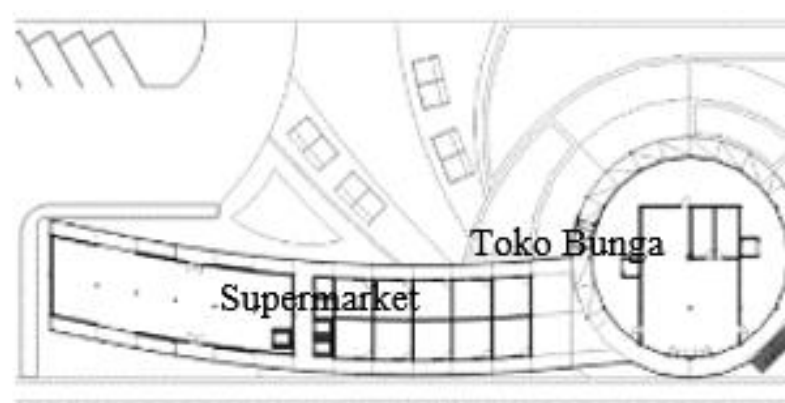

Gambar 5. Denah Lantai2 Agro Edu Tourism.

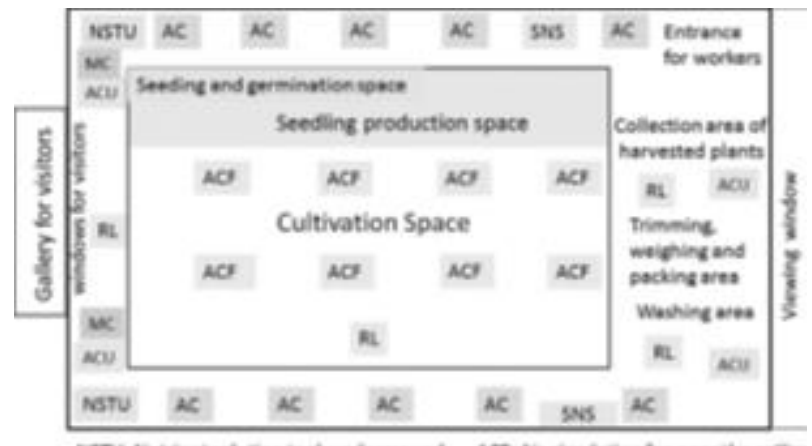

NSTU: Nutrient ielution tank undergound AC: Air cleculation tan near the ceilivy

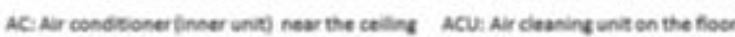
SNS: Sterliation unit for nutrient nolution on the floor R: Room lemps MC Monhoring camers

Gambar 6. Tipologi Denah Plant Factory with ArtificialLighting.

3. Lokasi harus bisa dijangkau oleh teknologi dan sumber daya yang dibutuhkan untuk melakukan pembangunan dan pengoperasian objek arsitektur.

4. Memiliki posisi yang strategis untuk melakukan kegiatan perdagangan dan jasa komersial untuk memudahkan kegiatan pemasaran bahan pangan.

Berdasarkan kriteria lahan, penulis memilih sebuah site yang berada di wilayah Jalan Kayoon. Lahan berada di eksisting pasar bunga Jalan Kayoon. Fasilitas yang terdapat pada eksisting berupa Pertokoan bunga segar, pertokoan bunga imitasi, warung-warung, perumahan pemilik toko bunga dan TPS kayoon.

Pendekatan desain yang digunakan adalah sistem "Plant Factory with Artificial Lighting (PFAL). Istilah "Plant Factory with Artificial Lighting (PFAL)" mengacu pada fasilitas produksi tanaman dengan insulasi termal dan ruang tertutup seperti gudang [1]. Cara penanaman adalah dengan menggunakan panel seperti rak-rak yang dilengkapi dengan lampu elektrik yang ditumpuk secara vertikal. Alat-alat yang dibutuhkan untuk PFAL adalah berupa AC, AC fans, CO2, unit larutan nutrisi, dan environmental control unit (Gamb ar 6) [1].

Cara bertanam dengan PFAL akan meningkatkan efisiens i penggunaan lahan. Desain akan dirancang berdasarkan aturan-aturan dasar dari sistem indoor vertical farming atau PFAL. Selain sistem PFAL, Antrophometrics dan Ergonomics digunakan sebagai acuan dalam menentukan ukuran sebuah ruang agar desain bisa dibuat dengan penggunaan lahan se-efektif mungkin (Gambar 7). Pada desain diterapkan seperti pada lebar ramp dan lebar walkway pada cultivation room.

Metode yang digunakan pada perancangan objek arsitektural adalah metode Architectural Programming yang ditulis oleh Donna P. Duerk. Metode ini penulis gunakan dari tahap pencarian fakta dan is u hingga ke tahap menentukan 


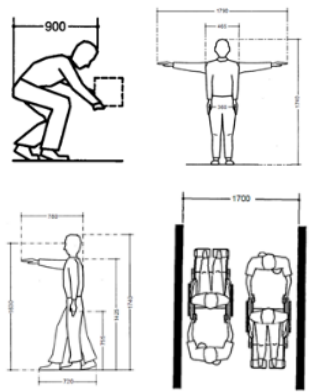

Gambar 7. Antrophometrics dan Ergonomics.

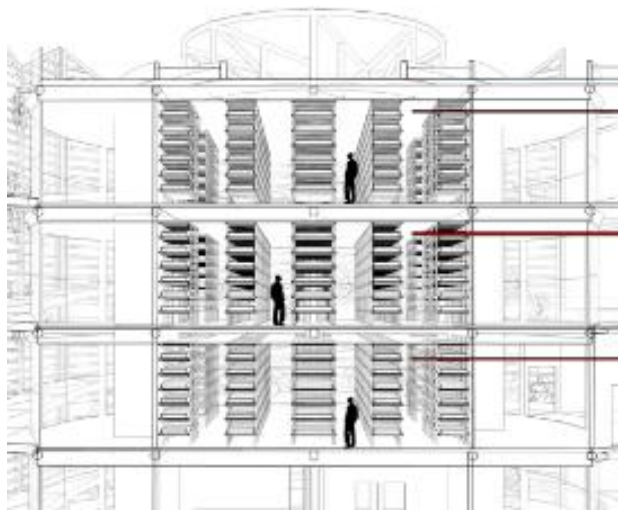

Gambar 8. Potongan AreaAgro Edu Tourism.

konsep yang akan digunakan pada desain. Konsep-konsep yang didapatkan diteruskan dengan metode zonasi.

Secara keseluruhan area pada desain dibagi menjadi dua zona, yaitu area Agro-Edu-Tourism (AET) dan area Plant Factory with Artificial Lighting (PFAL). Area AET bersifat publik, diperuntukkan untuk aktifitas edukasi dan wisata. tatanan ruang dan fasilitas yang disediakan dipertimbangkan berdasarkan fungsitersebut. Area PFAL bersifat lebih privat, diperuntukkan untuk operasional fasilitas dan sebagai fokus produksi tanaman. Tatanan ruang dan fasilitas yang disediakan dipertimbangkan berdasarkan fungsi tersebut.

Sistem objek arsitektural di desain menggunakan metode tipologi. Jacques Nicolas - Louis Durand mengemukakan bahwa teori tipologi melihat arsitektur sebagai seni menyusun elemen-elemen yang telah ditentukan [4]. Dalam desain ini elemen-elemen yang telah ditentukan adalah kebutuhan-kebutuhan sistem dan ruang untuk vertical farming. Kebutuhan sistemdan ruang ditentukan dari tipologi vertical farming dan preseden vertical farming yang telah dibangun. Tipologi yang digunakan pada desain adalah organisasi tipe grower, institution dan konsultasi. Perletakan berada di rooftop, interior, fasad dan on ground. Exposure yang digunakan adalah exposed dan closed. Medium tumbuh yang digunakan adalah hidroponik.

Konsep makro yang digunakan dalam perancangan objek arsitektural adalah konsep efisiensi lahan. Dalam konsep ini, kegiatan farming yang biasanya dilakukan secara horizontal di lakukan secara tumpukan vertikal untuk efisiensi lahan (Gambar 8).

Konsep makro kedua yang digunakan adalah penyamaan pola bangunan bertingkat dan taman, sehingga bangunan memiliki kesan seperti pola taman yang ditarik ke atas. Harmonis asi antara taman dan bangunan bertingkat didukung oleh penggunaan ruang void di seluruh lantai 1 pada area AET.
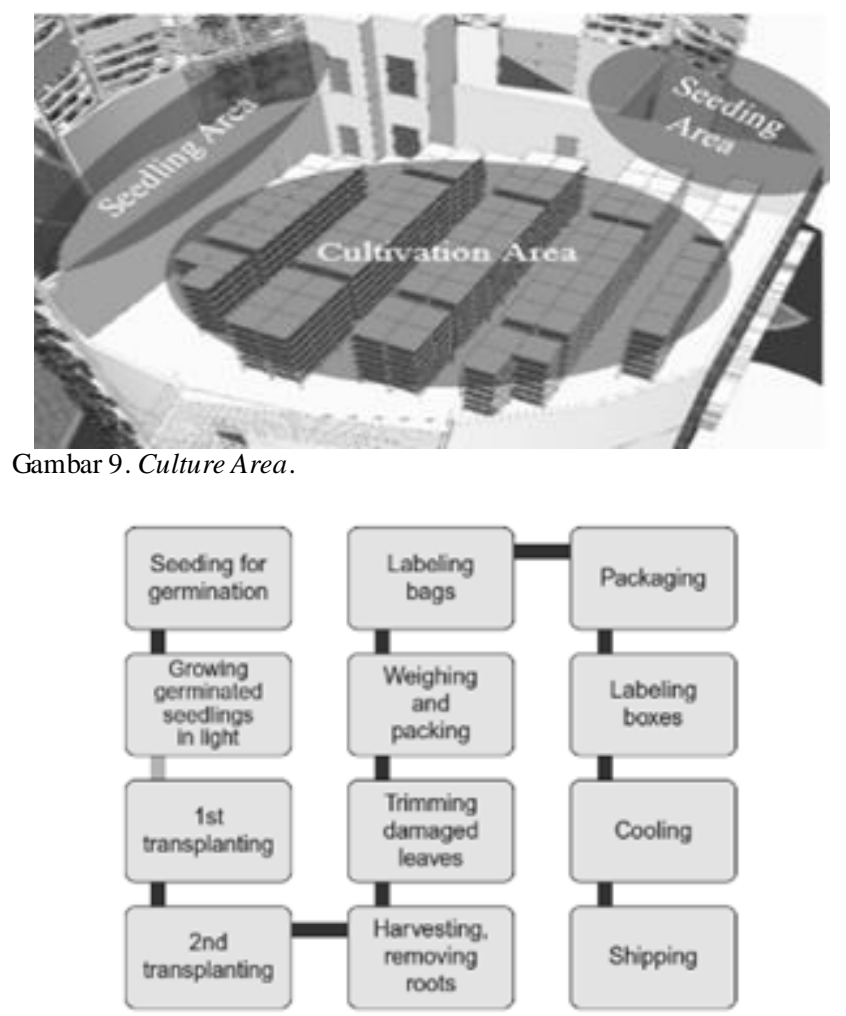

Gambar 10. Proses Vertical Farming.

\section{HASIL RANCANGAN}

\section{A. Culture Area}

Perbandingan luas seeding area, seedling area dan cultivation area adalah 1:12:50 (Gambar 9) [1]. Perbandingan ini menjadi pedoman dalam menentukan luasan area masing-masing. Tiga area ini dirancang pada lantai yang sama untuk mempermudah proses transplantasi tanaman yang dilakukan 2 kali, yaitu setelah tahap seeding ke area seedling dan setelah tahap seedling ke area cultivation (Gambar 10).

Tanaman yang telah siap dipanen akan dikirim ke ruang cuci untuk selanjutnya dikemas dan disimpan sebelum dijual. Ukuran panel yang digunakan adalah 1 x 1 x $0.5 \mathrm{~m}$ yang terdiri dari 6 tingkat. Panel dilengkapi dengan lampu LED atau flouroscence. Walkway selebar $1.2 \mathrm{~m}$, dengan standar lebar minimal $1 \mathrm{~m}$ (Gambar 11).

\section{B. Rainwater Harvesting}

Air hujan diteruskan ke rainwater harvest \& treatment. Pada bagian ini terdapat katup yang terhubung dengan Sungai Kalimas. Jika air pada penyimpanan penuh maka katup akan terbuka dan air akan mengalir ke sungai. Pipa penghubung antara tempat penyimpanan dibuat miring ke bawah ke arah sungai, agar air sungai tidak mengalir ke area penyimpanan (Gambar 12).

\section{SecondarySkin}

Bagian luar bangunan dilapis dengan sunscreen yang dilapisi tumbuhan menjalar sehingga membentuk green facade yang bertujuan untuk mengurangi panas cahaya matahari yang masuk dan mereduksi cahaya untuk kenyamanan pengunjung dalam melihat isi vertical farming dari balik kaca (Gambar 13). 


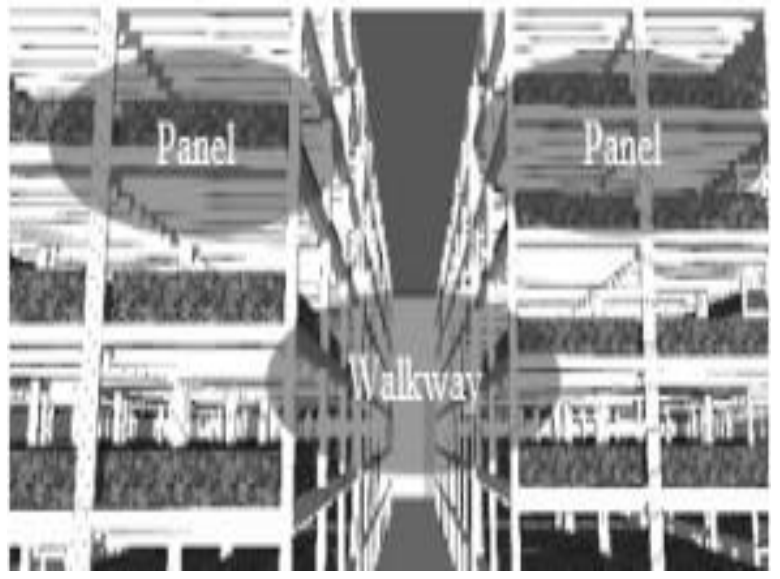

Gambar 11. Panel Vertical Faming.

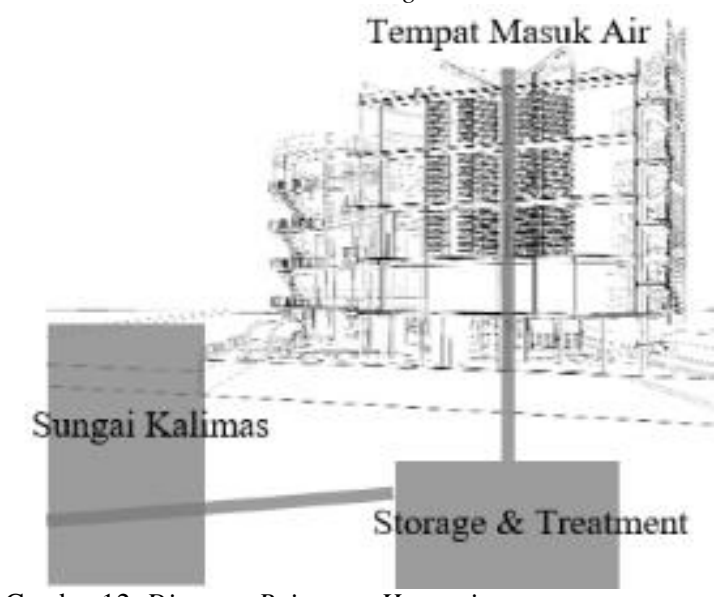

Gambar 12. Diagram Rainwater Harvesting .

\section{A. Sirkulasi Vertikal}

Menggunakan ramp selebar $2 \mathrm{~m}$ sehingga sirkulasi terasa nyaman dan bisa diakses oleh pengguna kursi roda. Sebelu m masuk pengunjung juga bisa melihat-lihat kondisi vertical farming dari balik kaca (Gambar 13). Selain ramp juga digunakan lift barang dan lift karyawan. Lift karyawan hanya di rancang di bangunan PFAL yang terdiri dari 7 lantai.

\section{B. Pengolahan Sampah}

Sampah organik sisa pertanian dan penjualan bunga dibuang ke TPS pinggir lahan untuk selanjutnya diolah di tempat pengolahan pupuk kompos belakang TPS. Pupuk dapat digunakan pada taman bunga yang merupakan salah satu sumber bunga yang dijual. Sehingga membentuk siklus tertutup.

\section{Lift Karyawan}

Lift untuk karyawan bisa diakses dari lantai 1 dan lantai 7. Untuk mengakses lift karyawan tidak perlu masuk air shower terlebih dahulu (Gambar 14).

\section{Lift Petani}

Karyawan yang mengurus culture area akan disebut “petani”. Untuk mengakses lift ini, petani perlu melalui ruang ganti dan air shower terlebbih dahulu (Gambar 14).

\section{E. Lift Barang}

Lift barang yang digunakan ada 2 tipe, yaitu lift barang 1 pintu dan 2 pintu depan belakang. Setiap bangunan memiliki minimal satu lift barang untuk memudahkan pemindahan barang.
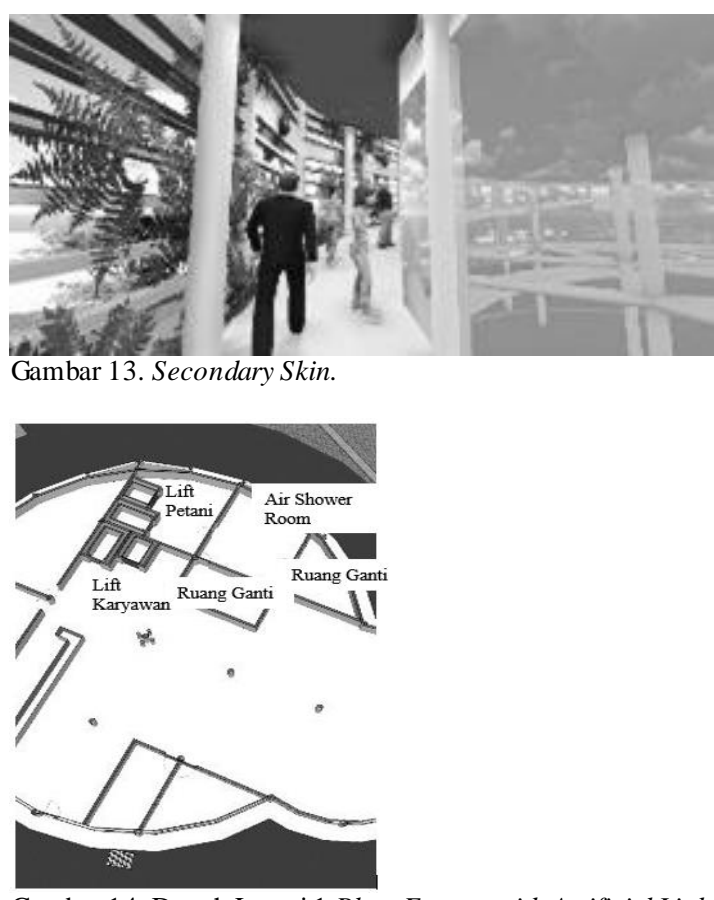

Gambar 14. Denah Lantai 1 Plant Factory with Artificial Lighting.
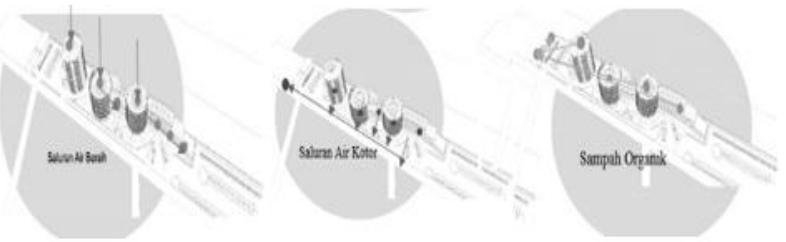

Gambar 15. Diagram Air Bersih, Air Kotor dan Sampah.

\section{F. Lantai Dasar}

Lantai dasar pada area AET dibuat void, sehingga sirkulasi lantai dasar lebih leluasa dan memperjauh jarak pandang. Void ini dimanfaatkan sebagai ruang serba guna, seperti untuk penyuluhan, seminar, pameran serta area komunal.

\section{G. Sistem Air Bersih}

Air bersih diterima dari hasil rainwater harvesting pada musim hujan dan PDAM pada musim kemarau (Gambar 15).

\section{H. Sistem Air Kotor}

Air kotor mengikuti skema pada umumnya, sebagian masuk ke septic tank dan sebagian masuk ke saluran air kota. Air sisa cuci tanaman dan air yang digunakan untuk hidroponik bisa digunakan ulang (Gambar 15).

\section{Sistem Pengolahan Sampah}

Sampah dibuang pada TPS. Sampah anorganik akan diteruskan ke TPA sedangkan sampah organik akan diolah di tempat pengolahan pupuk kompos (Gambar 15).

\section{J. Sistem HVAC}

Sistem HVAC dilengkapi dengan sistem plumbing untuk recycle air hasil penguapan. Sehingga bisa digunakan kembali untuk hidroponik.

\section{K. Sistem Kelistrikan}

Bangunan memiliki fungsi yang hampir berfungsi selama 24 jam tentu kebutuhan genset diperlukan ketika terjadi pemadaman. Genset ditempatkan pada ruang utilitas. 


\section{KESIMPULAN}

Vertical farming yang dirancang menggunakan lahan untuk agrowis ata yang belum berkembang secara maksimal, kemudian program yang telah ada di eksisting akan diasimilasikan dengan program desain yang dirancang. Dalam proses perancangan efisiensi penggunaan lahan selalu diperhatikan, dalam desain ini diwujudkan dengan bentuk bangunan yang bertingkat, penggunaan bentuk bangun melingkar yang efisien dan perancangan ruang berpedoman pada antrophometrics dan ergonomics. Kenyamanan pengunjung juga diperhatikan sepeti dengan penggunaan ramp sebagai salah satu sistem sirkulasi vertikal, void pada lantai dasar sehingga jarak pandang dan sirkulasi pengunjung lebih leluasa. Sehingga terciptalah vertical urban farming yang efisien dan nyaman.

\section{DAFTAR PUSTAKA}

[1] Kozai, N. Toyoki, Genhua, and M. Takagaki, Plant Factory An Indoor Vertical Farming System for Efficient Quality Food Production. London: Academic Press, 2016.

[2] Pemerintah Kota Surabaya, "Perda Tata Ruang dan Wilayah Kota Surabaya Tahun 2010 - 2030," Surabaya, 2010.

[3] Pusat Data dan Sistem Informasi Pertanian, "Statistik Lahan Pertanian Tahun 2009-2013,” Jakarta, 2014.

[4] K. Jormakka, Basics Design Methods. Boston: Birkhäuser, 2003. 